\title{
ATIVIDADES INTERDISCIPLINARES EM PROL DA FORMAÇÃO DA CONSCIENTIZAÇÃO DO DESTINO ADEQUADO PARA O LIXO
}

\section{Kátia Cristina Nascimento ${ }^{*}$, Bruna Silva Lopes ${ }^{2}$, Roziane Nascimento da Souza ${ }^{3}$, Cinthia de Paula Marques ${ }^{4}$}

${ }^{1}$ Graduanda do curso de Licenciatura em Química da Universidade Federal de Goiás

- Regional Catalão. Catalão, GO, Brasil. "(katiacristinaquimica@gmail.com)

${ }^{2}$ Graduanda do curso de Ciências Biológicas da Universidade Federal de Goiás -

Regional Catalão. Catalão, GO, Brasil.

${ }^{3}$ Graduanda do curso de Letras - Português da Universidade Federal de Goiás -

Regional Catalão. Catalão, GO, Brasil.

${ }^{4}$ Professora da Escola Municipal Nilda Margon Vaz. Catalão, GO, Brasil.

Recebido em: 06/04/2018 - Aprovado em: 10/06/2018 - Publicado em: 20/06/2018

DOI: 10.18677/EnciBio 2018A131

O presente trabalho foi realizado com alunos do $3^{\circ}$ Ano do ensino fundamental na "Escola Municipal Nilda Margon Vaz" situada na cidade de Catalão-GO. As ações tiveram por base a metodologia do projeto intitulado: Práticas Pedagógicas e Educação Ambiental: a criança como agente transformador/multiplicador. Foram feitas intervenções interdisciplinares relacionadas com a problemática do lixo. As atividades propostas foram trabalhadas de forma interdisciplinar, envolvendo as áreas de português, geografia, matemática, história, ciências e artes, mostrando o conceito da palavra lixo e afirmando a importância de não jogar lixo nas ruas. Corroborando para que os alunos percebessem que o lixo que produzem é problema de cada um e que se não tomarem a decisão de cuidar da cidade que moram, poderão sofrer graves consequências. Foram realizadas várias dinâmicas para se trabalhar os materiais recicláveis e a cor das lixeiras, o que contribuiu para uma significativa aprendizagem. Pode-se afirmar que as metas do projeto foram satisfatórias, percebeu-se claramente que a "semente" da importância dos cuidados que se deve ter com o lixo foi plantada, visto que, os alunos foram bastante comprometidos durante as tarefas revelando que compreenderam o quão é importante tratar o lixo, pois a qualidade de vida de toda sociedade depende disso, fortalecendo a ideia de que são agentes participativos, integrantes, conhecedores e sobretudo responsáveis pela preservação do Meio Ambiente.

PALAVRAS-CHAVE: alunos; aprendizagem; meio ambiente.

\section{INTERDISCIPLINARY ACTIVITIES FOR THE TRAINING OF AWARENESS OF ADEQUATE DESTINATION FOR GARBAGE}

\begin{abstract}
The present work was carried out with $3^{\circ}$ year students of elementary in the school Municipal "Nilda Margon Vaz" located in the city of Catalão-GO. The actions were based on the methodology of the project titled: Pedagogical Practices and
\end{abstract}


Environmental Education: the child as a transformer / multiplier agent. Interdisciplinary activities related to the problem of waste were developed. The proposed activities were worked in an interdisciplinary way, involving the areas of Portuguese, geography, mathematics, history, science and arts, showing the concept of the word trash and affirming the importance of not throwing trash in the streets. Corroborating for students to realize that the garbage they produce is everyone's problem and if they do not make the decision to take care of the city they live in, they can suffer serious consequences. Several dynamics were performed to work the recyclable materials and the color of the dumps. This contributed to meaningful learning. It can be stated that the implementation of the project was satisfactory, since it is notable that from the activities developed, the "seed" of the importance of the care that we should have with the garbage was planted, since, the students were very compromised during the tasks revealing that they understood how important it is to treat garbage, since the quality of life of every society depends on this, strengthening the idea that they are participatory agents, members, knowledgeable and above all responsible for the preservation of the Environment.

KEYWORDS: students, learning, environment.

\section{INTRODUÇÃO}

A maior virtude de um país, sem dúvida, é a Educação. Todavia há o reconhecimento de que o projeto educacional brasileiro é falho e a educação oferecida para as crianças e adolescentes é de baixa qualidade. As autoridades educacionais enfatizam a emergência de mudanças (MALDANER, 2006). Para tanto, a interdisciplinaridade é uma proposta inovadora, um meio facilitador para o ensino, uma forma de transmitir o conhecimento sem fragmentar as disciplinas, fazendo uma contextualização a partir de uma inter-relação entre os saberes populares e os conteúdos ministrados na escola (SADOYAMA, 2015).

Nessa perspectiva, Fazenda (2013), enfatiza que a atitude interdisciplinar é caracterizada pela ousadia da busca, da pesquisa realizada coletivamente que transforma a insegurança num exercício do pensar, num construir, e essa atitude consegue superar as barreiras da interdisciplinaridade pelo desejo de criar, inovar, de ir além. Segundo Coimbra (2005):

\footnotetext{
O tema comum, extraído do cotidiano, integra e promove a interação de pessoas, áreas, disciplinas, produzindo um conhecimento mais amplo e coletivizado. As leituras, descrições, interpretações e análises diferentes do mesmo objeto de trabalho permitem a elaboração de um outro saber, que busca um entendimento e uma compreensão do ambiente por inteiro (COIMBRA, 2005).
}

Entretanto, o ensino integrado, rompe com o isolamento entre as disciplinas permitindo um consenso entre os discentes que é compreender o motivo de estudar certos conteúdos. A maioria dos estudantes durante a vida acadêmica sempre questionam a finalidade de aprender algumas matérias, já que não enxergam nenhuma utilidade prática em algumas abordagens. A aprendizagem para ser significativa precisa fazer um vínculo entre a teoria, a prática e o cotidiano (DIAS, 2016). Para Dias et al., (2016), envolver com educação ambiental é colaborar com o mundo e as pessoas que residem neste planeta, é aprimorar e esclarecer a forma de pensar, elevando a qualidade de vida de toda sociedade. De acordo com a Política Nacional de Educação Ambiental do Art. 1ํ da Lei nº 9795/1999 Educação ambiental tem por definição: 
[...]os processos por meio dos quais o indivíduo e a coletividade constroem valores sociais, conhecimentos, habilidades, atitudes e competências voltadas para a preservação ambiental, bem de uso comum do povo, primordial a uma vida saudável e sua sustentabilidade (BRASIL, 1999).

O termo sustentabilidade surgiu da necessidade de implementar medidas para solucionar problemas ambientais gerado pela forma do homem usufruir dos recursos que a natureza oferece sem se preocupar com o esgotamento desses recursos e com as futuras gerações. Dessa forma, o homem passou a conhecer e desenvolver métodos de como utilizar a natureza minimizando ao máximo os impactos (OLIVEIRA, 2013).

Para que seja efetivada a conscientização com uma participação ativa da sociedade faz-se necessário que a educação ambiental seja trabalhada com as gerações atuais e também com as futuras. Evidentemente, trabalhar problemas ambientais com as crianças é de extrema relevância, pois o quanto mais cedo elas conhecerem a existência desses problemas melhor será para que sejam formados cidadãos conscientes da necessidade de preservar e praticar cotidianamente a sustentabilidade (DIAS et al., 2016).

Para tanto, a natureza dispõe de um vasto eixo temático a ser discutido na escola (água, solo, ar, fauna, flora, resíduos...) dentre essas várias possibilidades encontra-se a polêmica do lixo, um impasse em que toda sociedade é protagonista. O que se vê hoje são as cidades, não somente as grandes metrópoles, mas também os municípios menores sem saber o que fazer com a produção de lixo. A quantidade de lixo doméstico gerado aumenta constantemente e já é um problema antigo da administração pública. Basta observar a quantidade de lixo armazenada nos domicílios diariamente (DIAS et al., 2016).

Uma das características principais da Educação Ambiental é a abordagem integradora e inter-relacionada aos problemas da natureza e sociedade, qualidades que mostram e reforçam o quanto é imprescindível aplicar o ensino interdisciplinar as questões ambientais (COIMBRA, 2005). Jardim e Fofonka (2013) destacam que os problemas ambientais estão vinculados com a forma indiscriminada do homem se apropriar da natureza correlacionando com inúmeros dilemas, como o lixo descartado inadequadamente que tem suscitado em excessivos impactos ambientais.

Almeida et al., (2013) afirmam que a crescente produção de resíduos está ligada ao exacerbado consumismo da população, quanto mais desenvolvida a sociedade maior é o poder de compra e com isso mais resíduos são gerados. Para a autora é preciso haver mudança de hábito sendo imprescindível uma fase de adaptação que ocorre paulatinamente. O objetivo desta pesquisa foi utilizar o ensino interdisciplinar para promover a sustentabilidade a partir da formação de futuros cidadãos conscientes do tratamento adequado para o lixo.

\section{MATERIAL E MÉTODOS}

O objeto de estudo para esse trabalho está fundamentado na execução do projeto: Práticas Pedagógicas e Educação Ambiental: a criança como agente transformador/multiplicador. A pesquisa foi realizada na escola municipal: Nilda Margon Vaz, instituição com 680 alunos do ensino fundamental, localizada desde o ano de 1982 na Avenida José Marcelino, no 96, Bairro Castelo Branco na cidade de Catalão Goiás. Foi escolhida uma turma do 3ํano do ensino fundamental composta 
por 26 alunos para desenvolvimento de um projeto interdisciplinar de conscientização ambiental relacionada com a problemática do lixo.

Os alunos tiveram oito aulas, sendo que o objetivo da primeira, foi obter os conhecimentos prévios sobre o tema educação ambiental. Realizou-se a leitura coletiva do livro: Poeminhas da Terra e promoveu-se uma conversa informal. Foi elaborado um cartaz com o nome "Patrulha Salvadora".

Para a segunda aula, foi trabalhada interdisciplinarmente a conscientização da quantidade exagerada de lixo que o homem tem produzido. Para tanto, utilizou-se um texto com o título: "Lixo: um problema de todos", trabalhou-se a leitura, o conceito da palavra lixo e foi explicado que cada tipo de resíduo tem sua forma correta de ser descartado. Fez-se um paralelo entre a quantidade de lixo produzida por dia da cidade de São Paulo e Catalão em relação a extensão territorial dessas cidades. Solicitou-se para um dos alunos representar na lousa a escrita numérica e por extenso dos números referentes as toneladas de resíduos de Catalão e São Paulo. Utilizou-se um mapa do Brasil para identificar a localização, o tamanho e a distância entre as duas cidades. Foi realizada uma dinâmica de grupo, chamada " ideia puxa ideia", neste momento os grupos disseram palavras-chave que já haviam sido proferidas durante a aula que foram escritas na lousa para construção de frases. Finalizou-se a aula com a pintura de um desenho do cascão descartando o lixo na lixeira.

A terceira aula abordou a importância da coleta seletiva. Trabalharam-se as cores da coleta seletiva. Em grupo, foram confeccionadas lixeiras com as cores da coleta seletiva utilizando latas de leite em pó, tinta guache, pincel e papel pardo. $O$ fim da aula consistiu na realização do jogo: "destino certo".

$\mathrm{Na}$ quarta e quinta aulas foram apresentadas soluções para minimizar a produção de lixo nas cidades. Para isso, os alunos assistiram ao filme: "Quixote Reciclado". Utilizando fantoches, foi exibida a peça teatral da história do filme. Uma "roda de conversa" foi organizada para esclarecer as questões ambientais apresentadas no teatro. Como avaliação, aplicou-se um questionário e desenharam a parte do teatro que mais gostaram.

A sexta aula abordou a questão da reciclagem. Nesta aula os alunos foram conscientizados da importância do reaproveitamento de resíduos (lixo) com uma atividade que envolveu a produção de outros objetos a partir do lixo. Representando um personagem de Quixote Reciclado (o catador), construíram um "porta-treco" com garrafas pet, cola, tesoura, tampinhas de garrafas pet, papel crepom e papel cartão de diversas cores.

A sétima e oitava aulas abordaram soluções para diminuir o acúmulo de lixo. Foi feita uma mini-horta com pneus velhos. Preparou-se o canteiro e realizou-se o plantio das mudas. O projeto iniciou-se no fim do mês de agosto e foi finalizado no início do mês de novembro do ano de 2017. As aulas não foram ministradas em dias sequenciados, pois o projeto não poderia atrapalhar as aulas cotidianas da turma. Cada aula teve duração de 2:30 h.

\section{RESULTADOS E DISCUSSÕES}

Concordando com Pelizzani et al., (2002), que para atingir a aprendizagem significativa é necessário relacionar o novo conteúdo com os conhecimentos prévios. Para isso, realizou-se a leitura coletiva do livro "Poeminhas da Terra", aprenderam um pouco sobre a cultura e as palavras indígenas adotadas pela língua portuguesa retratada pelo livro, como mostra a figura abaixo: 




FIGURA 1: Trabalho com livro "Poeminhas da Terra" e cartaz missão "patrulha salvadora".

Realizou-se uma "roda de conversa" informal em que os alunos demostraram possuir alguns conhecimentos teóricos e práticos sobre as maneiras de como tratar bem o lixo. Três alunos (as) disseram reciclar latas de alumínio, outro fez o relato de que a avó produz sabão com óleo usado, outros quatro mencionaram que há coleta seletiva em seu bairro, por isso ajudam seus pais a fazerem a separação do lixo.

Nesse primeiro contato, ficou claro que a execução do projeto seria uma missão, diante disso, colocaram o nome de "Patrulha Salvadora" sendo elaborado um cartaz, utilizando tinta guache para carimbar as mãos das crianças e fixar no papel.

O foco da segunda aula foi conscientizar as crianças da importância de diminuir a quantidade de lixo que o homem tem produzido, visto que, conscientizar as crianças na escola é essencial para aprenderem a respeitar a natureza e despertar valores básicos (OLIVEIRA et al., 2012). As atividades desenvolvidas abrangeram as áreas de português, geografia, matemática, ciências e artes. Nesse ponto, houve um paralelo entre a cidade de Catalão e São Paulo da quantidade de lixo gerado por dia relacionando com a população das duas cidades.

Perguntou-se na classe quem saberia escrever na lousa o número 18 mil toneladas que é o total de resíduos retirados das ruas de São Paulo todos os dias. Os alunos ficaram perplexos quando souberam que são recolhidos diariamente na cidade que residem (Catalão) 100 toneladas de lixo, o que foi aproveitado para implantar a preocupação em cada um de cuidar do lixo de sua moradia, pedindo para que os mesmos levassem tal preocupação para seus pais, familiares e amigos, fazendo com que o ensino ultrapasse os muros da escola, algo que é indispensável na interdisciplinaridade. Assim, Narciso (2009) esclarece que desenvolver projetos na escola que fazem parcerias que incluem as famílias e a sociedade contribui para um relacionamento harmonioso com o meio ambiente.

A utilização do mapa para mostrar a localização e a distância entre as cidades de São Paulo e Catalão revelou-se a necessidade de trabalhar mais com mapas em sala, pois, foi observado que vários alunos não possuíam familiaridade, visto que, não conseguiram identificar no mapa as cidades havendo a necessidade de marcar tais cidades no mapa. Os comentários sobre os sérios problemas ambientais que a 
cidade de São Paulo vem sofrendo em decorrência da maneira irresponsável de cuidar do lixo gerou reflexões importantes acerca dos problemas que já acontecem na cidade que residem (Catalão), especificaram a enchente que ocorre na Avenida Raulina Fonseca Pascoal que está localizada no centro da cidade e a Represa do Clube do Povo que possui odor forte e coloração escura, transtornos provenientes dos resíduos que a população joga nas ruas e são arrastados pelas águas das chuvas. Corroborando para todos reconhecerem que os detritos que são jogados fora é compromisso de toda a comunidade.

Logo após, procedeu a dinâmica de grupo "ideia puxa idéia", com formação de frases usando palavras que foram proferidas na explicação do conteúdo, momento que conferiu ter ocorrido de fato a conscientização devido aos alunos formarem frases interessantes como: "cidade limpa, cidade sem dengue". Terminouse a aula com a pintura do cascão personagem do desenho da Turma da Mônica, colocando o lixo na lixeira. Abaixo encontram-se imagens destes momentos:



FIGURA 2: Segunda aula da execução do projeto.

Em conexão com o exposto anteriormente, na terceira aula desenvolveu-se uma atividade prática para ensiná-los a separar adequadamente o lixo. Afinal, o lixo urbano é um empecilho na luta pela conservação do meio ambiente e sobrevivência humana (VIDAL; MAIA, 2006). Uma vez que, a coleta seletiva e a reciclagem cooperam para a conservação e preservação do meio ambiente (VIEIRA; TEIXEIRA, 2015) foram produzidas lixeiras coloridas de acordo com as cores da coleta seletiva, fazendo o uso de latas de leite em pó. Uma lixeira de cada cor foi aproveitada para a execução do jogo "destino certo", visto que, o lúdico é capaz de favorecer para a criança um autodesenvolvimento, contribuir em tomar decisões, aprender a conviver com regras, desperta a imaginação além de propiciar o convívio com o outro (FERREIRA et al., 2014).

O jogo consistiu em vendar os olhos do jogador, girá-lo com intuito de fazer com que perdesse a direção das lixeiras, e entregar a ele um dos materiais recicláveis (vidro, papel, plástico e metal), assim o jogador teve que andar até a lixeira e descartar adequadamente o material na lixeira de coloração correta, os 
outros participantes davam a direção da lixeira correta para o tipo de material que foi entregue para o jogador.

Assim pode-se afirmar que as atividades trilharam em uma boa direção, visto que, não houveram atividades sem retorno por parte das crianças. Foi perceptível o conhecimento absorvido, ao responderem alguns questionamentos ou quando eram solicitados a colaboração nas atividades em razão de sempre expressarem disposição e entusiasmo. As imagens abaixo reforçam essa etapa:
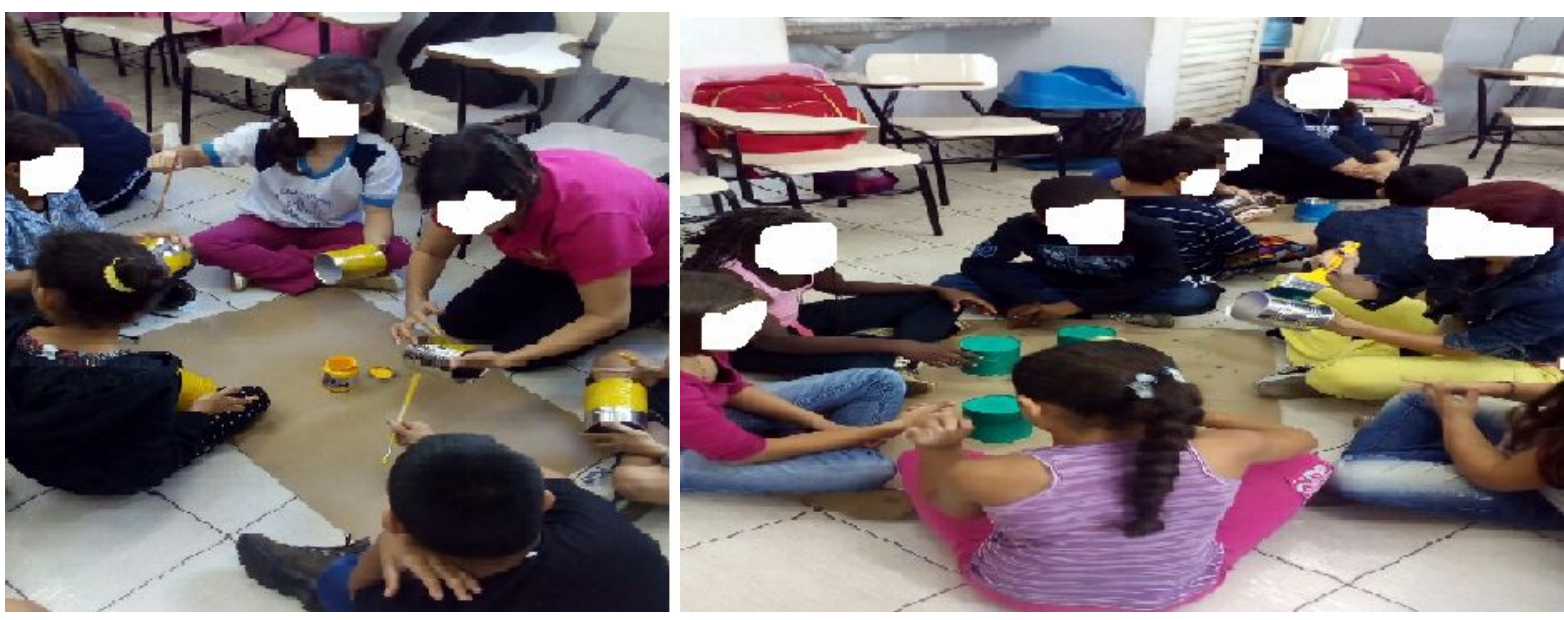

FIGURA 3: Confecção de lixeiras utilizando as cores da coleta seletiva.



FIGURA 4: Jogo dinâmico utilizando lixeiras da coleta seletiva.

A mídia é um recurso "indispensável para a melhor qualidade do ensino" (PAZZINI; ARAÚJO, 2013). Desse modo, para abordar a problemática da reciclagem, os alunos assistiram ao curta metragem "Quixote Reciclado", que é uma recriação de Dom Quixote. Todavia, alguns demonstraram não ter compreendido a história do filme, devido ao mesmo possuir duração de aproximadamente uma hora. Para esclarecer a abordagem do filme "Dom Quixote Reciclado" foi montada uma peça teatral utilizando fantoches para a apresentação. Ficou nítido que o interesse dos alunos com o teatro foi muito maior do que em relação ao filme, ocorrendo uma participação expressiva dos envolvidos, confirmando o poder dinâmico e interativo que o teatro possui. 
Quixote Reciclado retrata a questão da importância de reutilizar, deixa claro que o lixo não é algo ruim e que a humanidade só tem a se beneficiar quando o mesmo é separado adequadamente, podendo ser reaproveitado para diversas finalidades. Mostra também que é equivocado tratar o lixo como algo indesejável e inútil, contribuindo com a aprendizagem e desenvolvimento do saber crítico das crianças.

Ainda nessa mesma discussão, realizou-se uma "roda de conversa" muito produtiva sobre os assuntos retratados no teatro. As imagens abaixo revelam esses momentos:

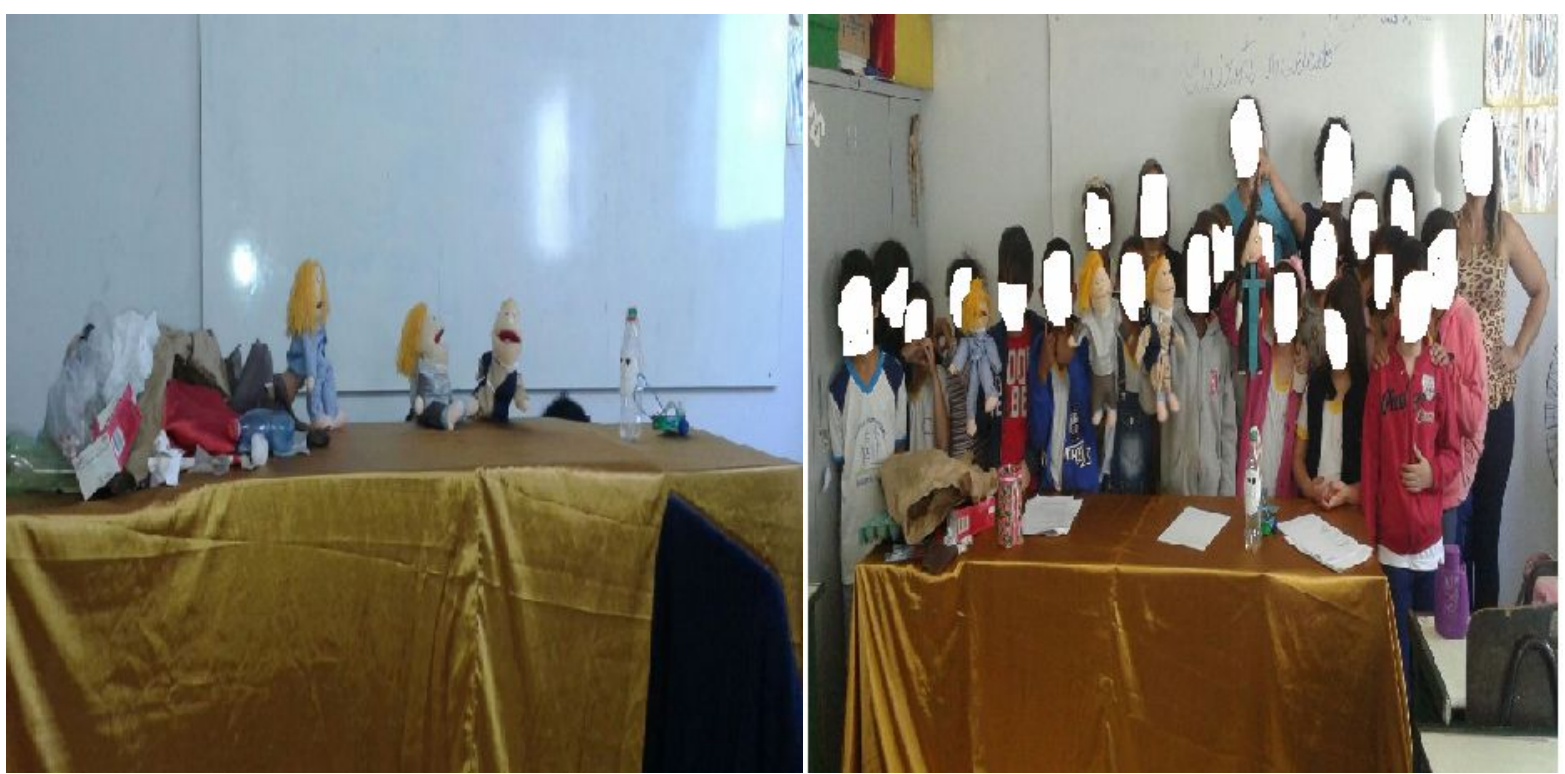

FIGURA 05: Apresentação de "Quixote Reciclado" em fantoches.

Sequencialmente foi entregue um questionário contendo 10 questões sobre os problemas que envolvem o lixo e estavam presentes na história do teatro, objetivando examinar o desempenho dos alunos. Neste dia 21 alunos frequentaram a aula e todos responderam ao questionário. O gráfico abaixo aponta os erros $\mathrm{e}$ acertos das questões:

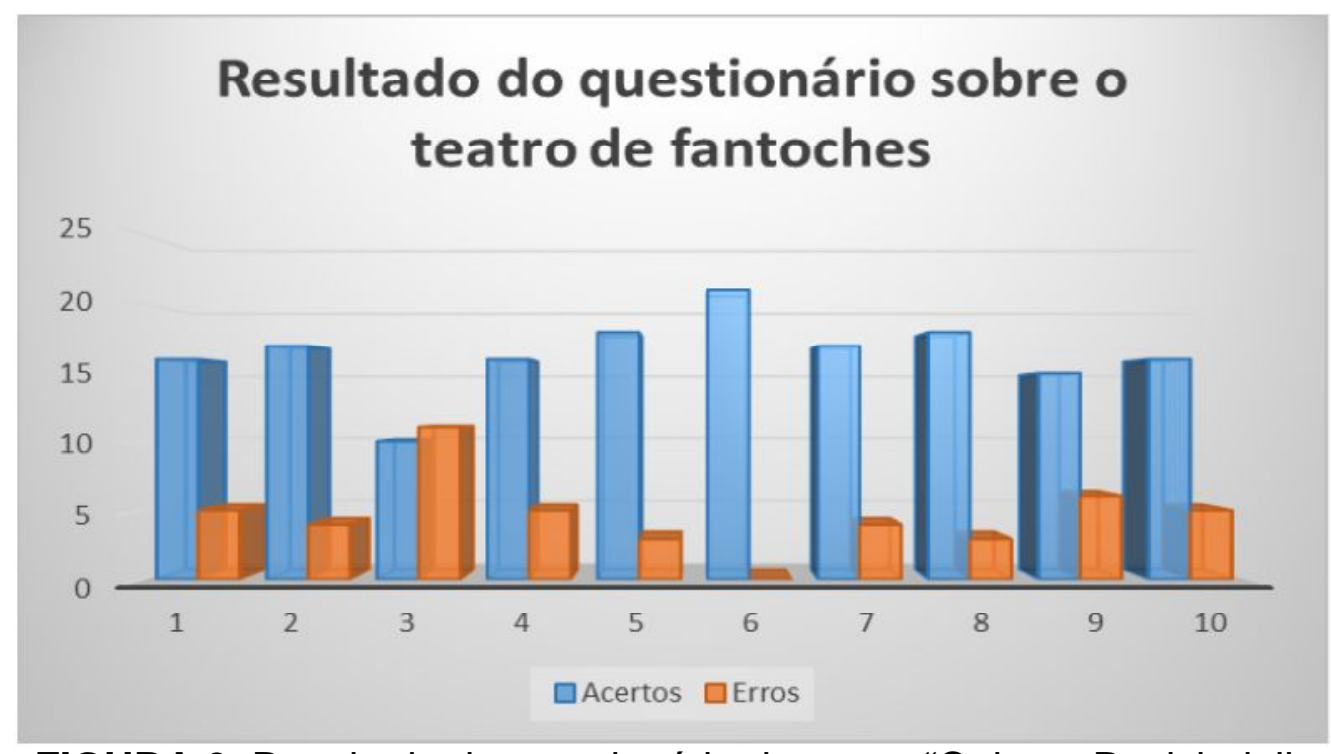

FIGURA 6: Resultado do questionário do teatro "Quixote Reciclado" 
Tendo em vista que os resultados obtidos a partir do questionário apresentaram bom desempenho, constatou-se que o teatro atingiu as expectativas, concordando com Bessa-Oliveira e Andrade (2015) ao afirmarem que o dinamismo teatral provoca um efeito muito maior na aquisição do conhecimento quando comparado com aulas desenvolvidas tradicionalmente. Para finalizar, desenharam e pintaram a parte da história do teatro com a qual mais se identificaram. Vale frisar, que muitos ilustraram a vitória do "bem" contra o "mal", em que o bem é o mago que apresenta as soluções para diminuir a quantidade de lixo e o mal é representado por um personagem maligno que tem a função de gerar o máximo de resíduos possíveis. Na aula seguinte, utilizando um personagem de "Quixote Reciclado" (o catador) construíram um "porta-treco" com materiais recicláveis, a seguir destaca-se o fruto desse trabalho:

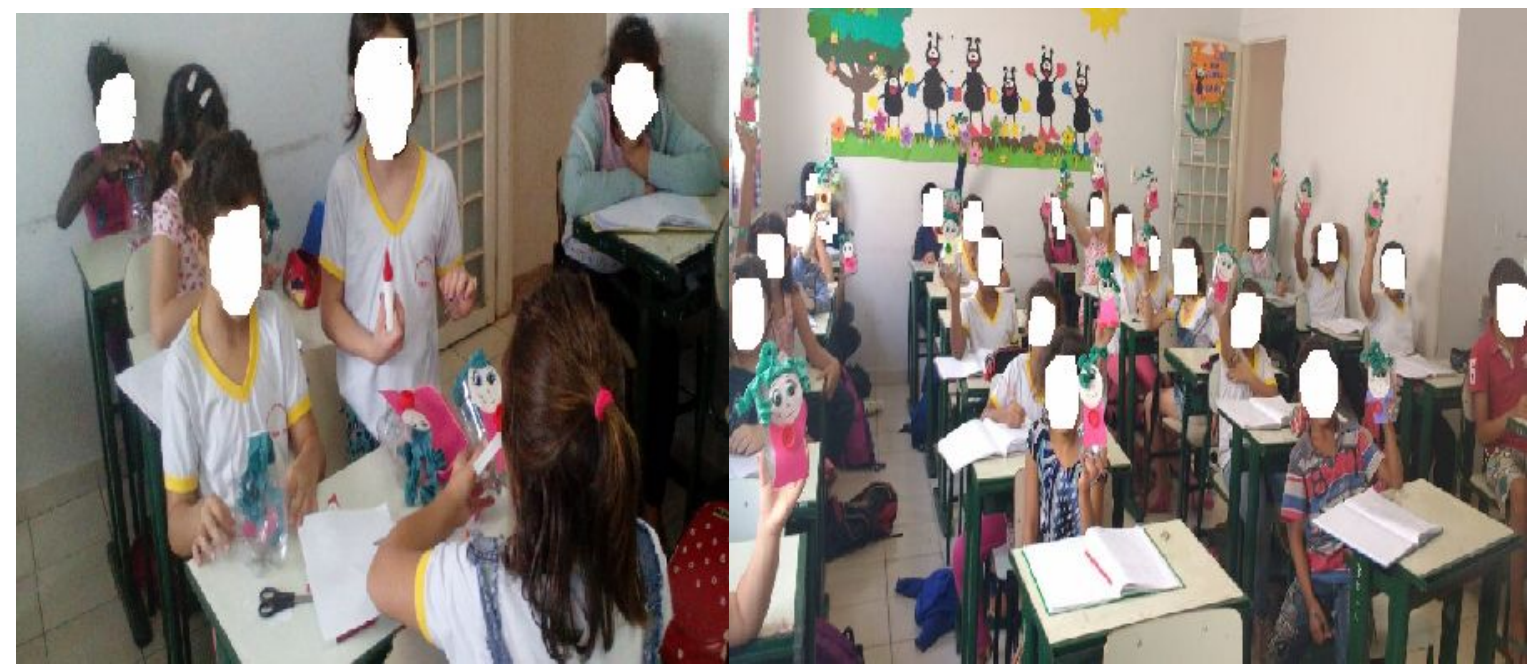

FIGURA 7: construção do "porta-treco".

Ainda na direção da reciclagem foi elaborada uma mini- horta, devido a escola não ter disponível um espaço apropriado para uma horta maior. Para isso, foram utilizados pneus velhos cortados ao meio, as partes foram utilizadas para desenhar uma flor (figuras abaixo). Nesse momento houve a participação de todos (preparação da terra com adubo e perfuração de buracos para a fixação de estaca de eucalipto para cercar a horta). Logo após ocorreu o plantio das mudas (dentro da flor feita de pneu) pelos alunos. Aproveitou-se do tema para explicar que as plantas produzem seu próprio alimento através da fotossíntese, diferentemente do homem que necessita da natureza para obter o seu sustento. Abaixo encontram-se imagens que evidenciam essa ocasião: 


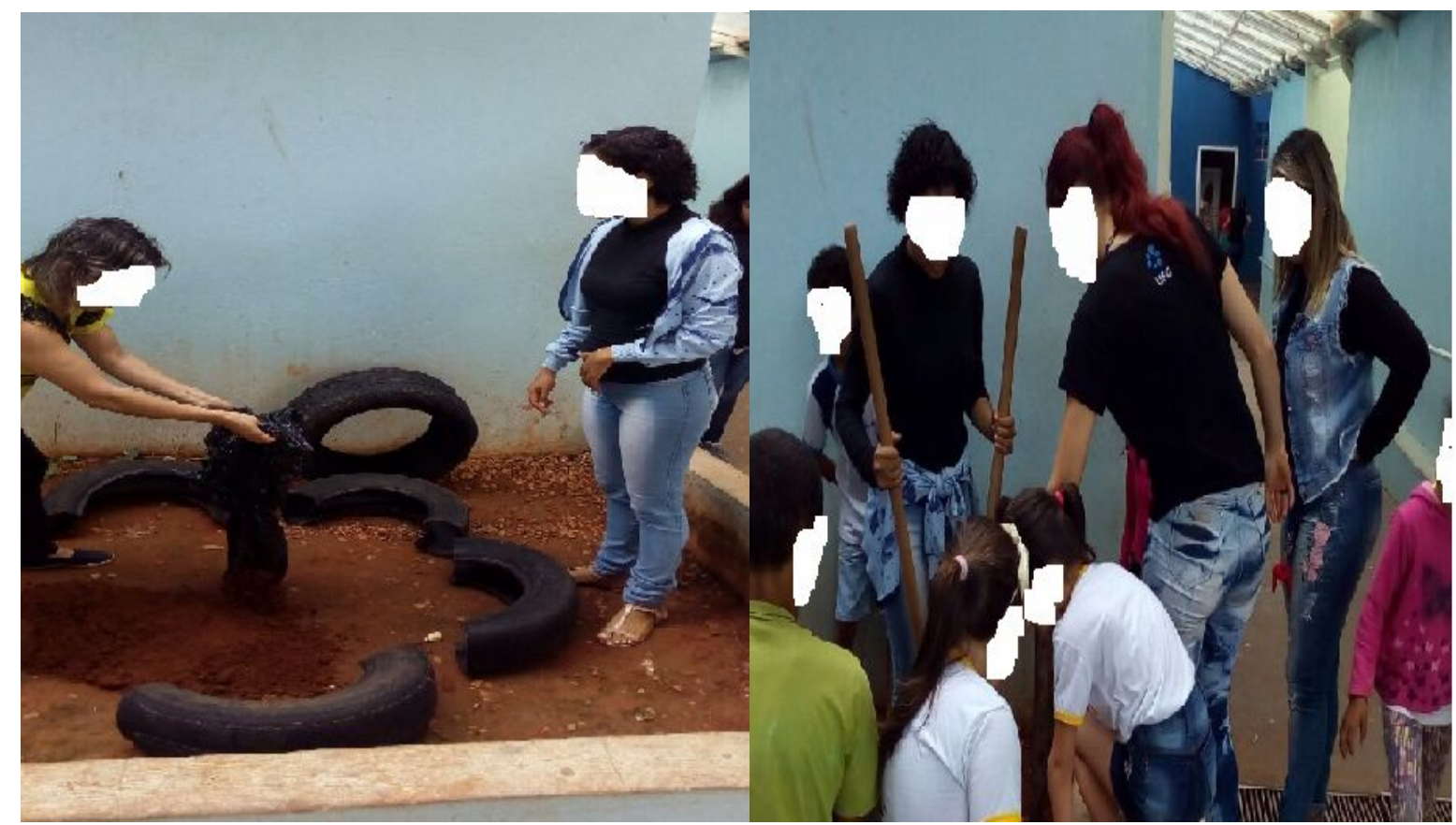

FIGURA 8: Montagem da pequena horta.

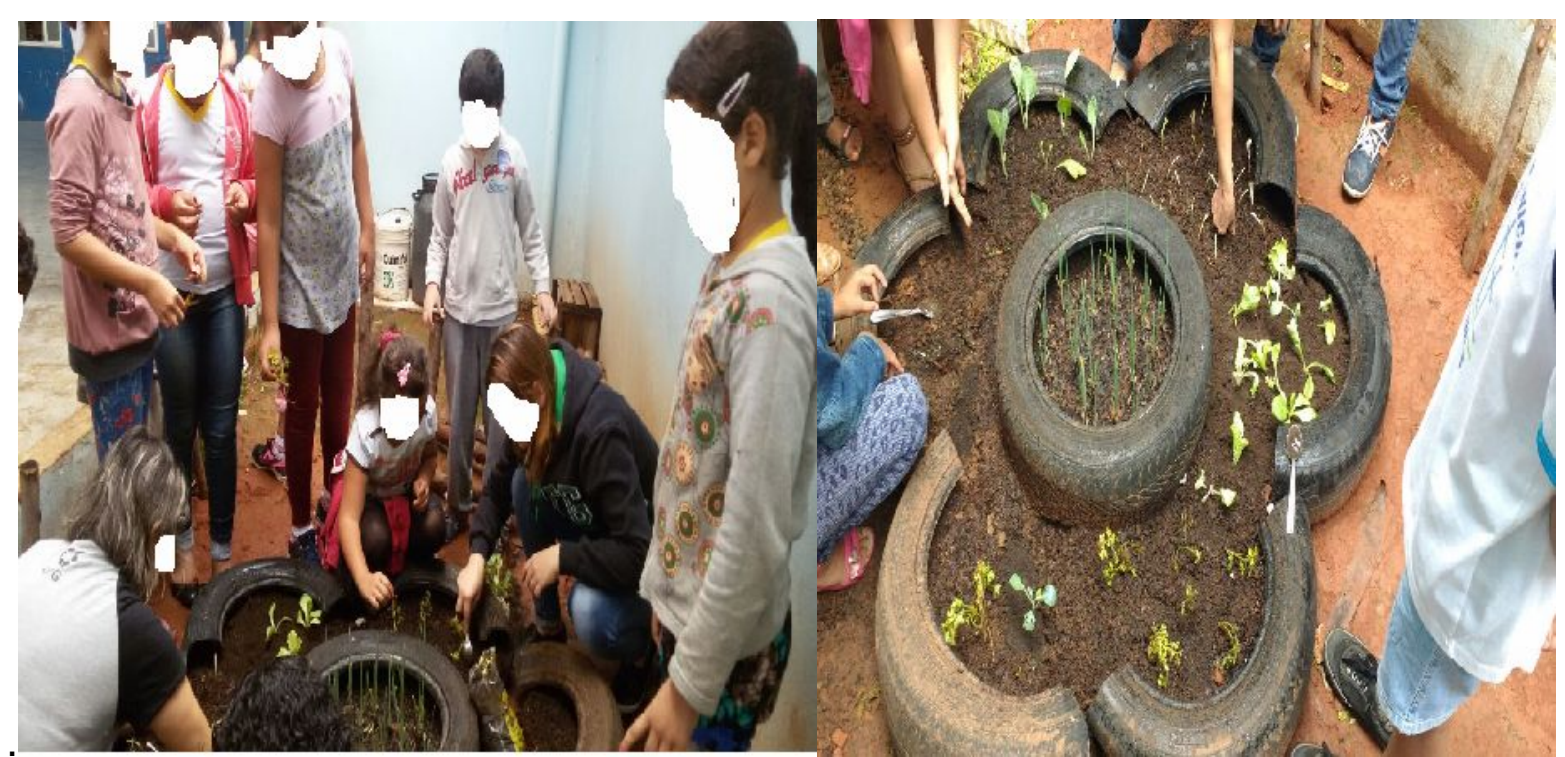

FIGURA 9: Finalização do primeiro plantio na pequena horta.

O projeto possibilitou o contato direto dos alunos com a horta, podendo preparar o canteiro, conhecer o solo, as plantas e compreender os cuidados necessários para o cultivo, além de estabelecer uma relação de respeito com a terra. A conscientização sobre a importância da horta na escola foi realizada a partir de atividades educacionais em sala de aula.

O envolvimento total dos alunos é um dos maiores resultados que se pode obter em um projeto. Os alunos puderam aprender a cuidar, partilhar experiências com os outros e ainda, construir o sentimento de "ser capaz", mostrando o valor do seu trabalho. Por fim, foi explicado que a horta orgânica não está finalizada, pois é um trabalho contínuo e diário, e as crianças compreenderam isso de forma exemplar. 
Com este trabalho percebeu-se que a Educação Ambiental e interdisciplinaridade fazem uma parceria importante no que tange para o avanço da educação, pois a lista de conteúdos que podem ser levados para sala de aula é bastante ampla e devem ser trabalhados coletivamente e por todas as áreas do conhecimento. Vale ressaltar, que atividades interdisciplinares sobre a educação ambiental requer um criterioso planejamento, visto que, o tema é bastante diverso para que não se cometa o erro de fragmentar os conteúdos e perder a essência interdisciplinar, retornando para o ensino multidisciplinar ou até mesmo ao tradicional.

\section{CONCLUSÃO}

As metodologias e didáticas aplicadas para o desenvolvimento das atividades obtiveram sucesso e aceitação, melhorando assim a absorção do conteúdo abordado. Com a participação ativa da turma, pode se dizer que os objetivos foram alcançados, e que a reflexão sobre o lixo foi lançada de forma reforçada, forma essa de colher frutos significativos em meio a sociedade.

A questão dos resíduos muitas vezes pode ser associada como descaso, mas, é a partir de ações ativas, levando a realidade para aqueles que ainda podem ser "lapidados", que são as crianças, é que de fato a sustentabilidade pode ser promovida. É imprescindível que se tenha em mente que essas crianças poderão fazer a diferença, pois, compreenderam muito bem o destino adequado para os resíduos.

O despertar para os cuidados e manutenção com as plantas da horta foi de grande relevância, pois tudo que foi passado realmente colocou-se em prática. A contribuição desse projeto para os envolvidos foi fortalecer e estabelecer novos e corretos conceitos sobre o descarte do lixo.

\section{REFERÊNCIAS}

ALMEIDA, E.; MONTANHA, S.; SANTANA, C.; SOARES, B. Educação Ambiental na escola: um estudo da relação entre a alimentação e a produção de resíduos. Revista Brasileira de Educação Ambiental. Rio Grande v. 7, n. 2, p. 131-149, 2013.

BRASIL. Ministério do Meio Ambiente: Conceitos de Educação Ambiental Política Nacional de Educação Ambiental - Lei no 9795/1999, Art. 1ํ. Disponível em: <http://www.mma.gov.br/educacao-ambiental/politica-de-educacao-ambiental>. Acesso em: 20 de dezembro de 2017.

BESSA-OLIVEIRA, M.; ANDRADE, T. Revitalização da Língua Materna Terena por Meio do Teatro Segundo o PCN-Arte/Teatro. Cadernos de Estudos Culturais, UFMS, v.7, n.13, p. 85-105, 2015. Disponível em: <http://www.seer.ufms.br/index.php/cadec/article/view/3412> Acesso em: 15/01/2018.

COIMBRA, A. Interdisciplinaridade e Educação Ambiental: Integrando Seus Princípios Necessários. REMEA-Revista Eletrônica do Mestrado em Educação Ambiental. Rio Grande do Sul, v.14. ISSN-1517-1256, 115-121p. jan/jun de 2005. 
DIAS, L.; LEAL, A.; JUNIOR, S. Educação Ambiental: conceitos, metodologia e práticas. $1^{\circ}$ ed. Tupã SP: ANAP, 2016.

FAZENDA, I. Práticas Interdisciplinares na Escola. 13ำ ed. São Paulo: Cortez, 2013.

FERREIRA, K.; CONDOTTA, R.; MONTEIRO, A. O Ensino Da Matemática $\mathrm{Na}$ Educação Infantil e a Ludicidade Na Abordagem do Processo. Unisanta Humanitas. v.3, n.1 p.62-81, 2014. Disponível em: <http://periodicos.unisanta.br/index.php/hum/article/view/277>. Acesso em: 15/01/2018.

JARDIM, V.; FOFONKA, L. Educação Ambiental e Gestão Dos Resíduos Sólidos da Construção e Demolição No Munícipio De Canoas/RS. ISSN 1678-0701. n. 44, Ano XII. Junho- agosto de 2013. Disponível em: <http://www.revistaea.org/artigo.php?idartigo=1485>. Acesso em: 12/01/2018.

MALDANER, A. A Formação Inicial e Continuada de Professores de Química: professor/pesquisador. Coleção educação em química. $3^{\circ}$ ed. ljuí: Editora Unijuí,2006.

NARCISO, K. Uma Análise Sobre a Importância de Trabalhar Educação Ambiental nas Escolas. Revista Eletrônica do Mestrado em Educação Ambiental. Universidade Federal do Rio Grande, FURG. ISSN 1517-1256, v. 22, janeiro a julho de 2009. Disponível em: https://periodicos.furg.br/remea/article/view/2807/1585. Acesso em: 01 de junho de 2018.

OLIVEIRA, E. Ciências Ambientais, Interdisciplinaridade e Sustentabilidade. $2013 . \quad$ Disponível em: <http://www.cpgls.pucgoias.edu.br/8mostra/Artigos/SOCIAIS\%20APLICADAS/Cienci as\%20Ambientais\%20Interdisciplinaridade\%20e\%20Sustent.pdf >. Acesso em: 27 de dezembro de 2017.

OLIVEIRA, M.; OLIVEIRA, B.; VILELA, M.; CASTRO, T. A Importância da Educação Ambiental na Escola e a Reciclagem do Lixo Orgânico. Revista Científica Eletrônica de Ciências Sociais Aplicadas da Eduvale Publicação Científica da Faculdade de Ciências Sociais Aplicadas do Vale de São Lourenço - Jaciara/MT Ano V, n.7, novembro de 2012 - Periodicidade Semestral - ISSN 1806-6283. Disponível em: <http://eduvalesl.revista.inf.br/imagens_arquivos/arquivos_destaque/OqT8ChKZ3qwi tpp_2015-12-19-2-22-31.pdf>. Acesso em 01 de junho de 2018.

PAZZINI, D.; ARAÚJO F. O Uso de Vídeo Como Ferramenta de Apoio ao EnsinoAprendizagem. Manancial Repositório Digital da Universidade Federal de Santa Maria (UFSM) - Centro de Tecnologia, Curso de Especialização em Mídias na Educação, EaD, RS, $2013 . \quad$ Disponível em: <https://repositorio.ufsm.br/handle/1/729>. Acesso em: 23 de junho de 2018.

PELIZZARI, A.; KRIEGL, M.; BARON, M.; FINCK, N.; DOROCINSKI, S. Teoria da Aprendizagem Significativa Segundo Ausubel. Revista PEC, 2(1), 2002, 37-42p. 
Disponível

em:

$<$ http://portaldoprofessor.mec.gov.br/storage/materiais/0000012381.pdf >. Acesso em: 31 de maio de 2018.

SADOYAMA, A. Ensino interdisciplinar: Um Mundo, Diferentes Olhares e Muitos Caminhos. $1^{\circ}$ ed. Ludomedia, 2015.

VIDAL, L.; MAIA, J. A Importância da Coleta Seletiva para o Meio Ambiente. Revista Hórus, v. 3, n. 1, p. 46-60, 2006, ISSN: 1679-9267. Disponível em: $<$ http://periodicosbh.estacio.br/index.php/revistahorus/article/viewFile/3932/1752>. Acesso em: 01 de junho de 2018.

VIEIRA, S.; TEIXEIRA, C. Educação Ambiental: Coleta Seletiva e Reciclagem no Ambiente Escolar. Anais II Congresso Nacional de Meio Ambiente de Poços de Caldas. v. 7, n. 1, p. 186, 2015, ISSN: 2317-9686. Disponível em: http://meioambientepocos.com.br/anais/186.\%20EDUCA\%C3\%87\%C3\%830\%20AM BIENTAL \%20COLETA\%20SELETIVA\%20E\%20RECICLAGEM\%20NO\%20AMBIE NTE\%20ESCOLAR.doc.> Acesso em: 23 de junho de 2018. 